\title{
The Public Politics of Opinion Research on Surveillance and Privacy.
}

\author{
Kevin D. Haggerty and Amber Gazso'
}

\begin{abstract}
This paper examines the political implications of methodological issues related to the now ubiquitous production of surveys dealing with issues of privacy and surveillance. It concentrates on how the distinctive attributes of a survey's response rate can skew the findings of such studies. The conclusion offers suggestions for how academics and activists might respond to this issue.
\end{abstract}

\section{Introduction}

On a July morning in 2003 a member of the public telephoned the Population Research Laboratory (PRL) at the University of Alberta. A major research unit, the PRL was at that time conducting the annual "Alberta Survey," an omnibus public opinion survey that covers a number of substantive areas on behalf of several researchers. On this day, however, someone who had been surveyed the previous night had taken the initiative to contact the PRL for more information about the survey. After reflecting further on the act of being surveyed, this individual was apparently increasingly concerned about a subset of questions on privacy, developments in surveillance, and their personal use of protective surveillance measures that we had included on the survey. They called to acquire more information about the purposes of the survey and for reassurances that their responses would remain confidential.

A prominent criticism of opinion research is that it can force people to commit to opinions on issues about which they had previously thought very little and which are only tangentially relevant to their daily routines. The above anecdote, however, accentuates the simple but important fact that surveys occasionally address matters that fundamentally structure how some people live their lives. We want to dwell on this point in the context of public opinion research on issues of surveillance and privacy (hereafter surveillance/privacy). In particular, we accentuate the relationship between survey response rates, contact rates and public concerns about surveillance/privacy. While response and contact rates are typically topics relegated to the more remote corners of statistical methodology, we suggest that they are considerably important to surveillance

1 Department of Sociology, University of Alberta, Edmonton, Alberta, Canada. mailto: Kevin.haggerty@ualberta.ca; mailto:amberg@ualberta.ca 
studies because of their broader political implications. Consequently, we aim to publicize these issues to a wider community of surveillance researchers and activists who might not otherwise be inclined to investigate the esoterica of survey methodology.

\section{Response Rates}

Since the popularization of public opinion polling, the issue of response rates has been a recurrent methodological concern (Groves and Couper, 1998). It has become even more prominent recently due to the escalating importance of public opinion polling in politics and marketing (Gandy, 2003; Herbst, 1998). Opinion surveys can now operate as a form of de facto plebiscite on important social issues. While not legally binding, politicians, activists and policy makers can pay remarkably close attention to such polls. Political action groups now contract for their own surveys to counter the hegemony of established interests. Entire policies are drafted, revised, abandoned and legitimated through appeals to public opinion. Opinion research is invoked in discussions of new governmental privacy legislation and commercial information initiatives. In the aftermath of the 9/11 terrorist attacks politicians have routinely appealed to "public sentiment" as manifest in various polls to justify hastily developed surveillance policies (Davis and Silver, 2004; Huddy, Khativ and Capelos, 2002). Indeed, Newman (2003) demonstrates how American policy elites aggressively worked to label the 9/11 events according to existing policy orientations and how, in a circular fashion, these typifications were reproduced in opinion polls that were then used to legitimate new policies.

One upshot of all of this polling is that the public now demonstrates increasing "study fatigue," manifest in either outright refusal to participate or incomplete participation in the myriad censuses, academic studies, opinion polls and market research which depend on citizens opening themselves up for scrutiny (Schleifer, 1986). This has led researchers to be increasingly concerned about levels of non-participation, typically referred to as a "response rate." There are several ways to calculate a response rate and many steps leading up to a final total (The American Association for Public Opinion Research, 2004). One of the most important differences in these formulas concerns whether non-response is defined as entailing instances where a potential participant actually voices her desire not to participate (more commonly referred to as the cooperation rate, i.e., the percentage of eligible respondents who agree to participate), or if it also includes those households that were approached but where no one answered the phone or responded to the e-mail (contact rate, i.e., the percentage of respondents who are contacted). In the latter calculation non-response rates are much higher than for those using the first formula. No matter how it is calculated, however, the decline in response rates is a well known North American phenomenon (Goyder, 2005). Response rates can now reach levels that are so low that a survey's representativeness is called into question (Herbst, 1993).

We contend that in few other fields does the issue of response rate have such self-evident political implications as in public opinion studies relating to issues of surveillance/privacy. The issue of response rate is ultimately a concern about randomness, representativeness and thus the generalizeability of findings to the broader population from which a sample was surveyed. Not everyone in the sampling frame can be located, or, if located, will agree to participate. For our purposes we are not specifically concerned 
with the issue of absolute response rates - the total percentage of the solicited population which participates in a study. Instead, our focus is on the randomness of the non-response. Depending on various factors relating to a survey's timing, the technology used, or the subject matter, certain classes of people will be differentially inclined to offer their voluntary consent to participate in a study (Groves, Cialdini and Couper, 1992). If the factors that lead certain groups of individuals to be disproportionately excluded from a survey are in some way related to the topic being studied, then the non-response can be a major methodological limitation. Internet surveys about computer usage, to take an obvious example, disproportionately exclude the opinion of people without computers, something that is itself correlated with various demographic and attitudinal variables. In such cases the differential response can be vitally important as it calls the representativeness of the study's findings into question (Dillman, 1991).

Public opinion surveys on surveillance/privacy are an extreme instance where we can expect a degree of important non-randomness to be structured into response rates. The very factors which these surveys seek to document - public attitudes towards surveillance/privacy - will, for a subset of the population, be intimately connected with behaviours that would disproportionately predispose them to be excluded from such studies. Individuals concerned about increasing surveillance or reduced privacy rights would, for example, be expected to have a greater penchant for unlisted telephone numbers. This would then exclude them from studies that rely on public listings to develop a sample, something which is of particular concern with on-line opinion surveys, since potential participants are often drawn from commercially complied lists of internet addresses (Wall, 2006). Such lists (or sampling frames) contain fewer individuals with heightened concerns about surveillance/privacy, as people with such attitudes tend to be more cautious about participating in the types of internet promotions, contests, scams, and "free offers" that result in their e-mail address being recorded on such commercial lists (Howard, Carr and Milstein, 2005). Even if researchers do acquire contact information for potential participants, personal privacy concerns tend to manifest themselves in a disproportionate tendency for some individuals to screen telephone calls or use computer software to automatically filter or block unsolicited electronic messages - in the process also screening themselves out of the survey sample. Finally, even if a potential participant is contacted, citizens with elevated concerns about surveillance/privacy would more routinely decline to participate. The end result might easily involve a sample where individuals who we might characterize as being "pro-surveillance" are over-represented while a disproportionate number of individuals who have "anti-surveillance" attitudes are excluded.

Existing American research has already documented the importance of this issue. Goyder and Leiper (1985) have detailed a significant correlation between the historical decline in survey response and the rise in public anxieties about privacy. Individuals with heightened privacy concerns also have a statistically significant reduced likelihood of returning the decennial census forms (Coupler, Singer and Kulka, 1998; Singer, Hoewyk and Neugebauer, 2003). The implications of these trends are particularly germane to studies that explicitly seek to detail attitudes on privacy and surveillance.

Such structured disproportionately in response rates should not be surprising. Surveys are themselves essentially a form of surveillance that some individuals routinely interpret as a 
privacy invasion. The issue of differential response in this context represents a classic instance of a methodological difference that can produce a practical and political difference. This is because we can expect that the people who systematically make themselves unavailable for such studies would be precisely those individuals with the greatest concern about surveillance/privacy. Findings for such studies are consequently skewed towards what we might characterize as a "pro surveillance" position. It is therefore particularly alarming to hear politicians appeal to the results of such surveys to justify new security measures as something the public wants.

Issues relating to privacy and surveillance have become hot button political issues (Haggerty and Ericson, 2006). Such policies are developed through recurrent examinations of, and appeals to, public opinion. Only recently, for example, Canada's premier national newspaper, The Globe and Mail, commissioned an opinion poll on Canadian attitudes towards, and opinions about, security and civil liberties. One of its prominent findings was that $72 \%$ of respondents supported having CCTV cameras in public spaces. No mention, however, was made of either the contact rate or response rate for this survey. After making some persistent inquires about this study we found that it had a response rate of only 11.6 per cent. That is, to interview 1,056 respondents over 12,000 eligible numbers had to be called. Most of these non-contacts are a result of people not answering the phone or having calls directed to answering machines - practices that are often attributed to call screening. Ultimately, 4,356 individuals were contacted and asked to participate. Fully 3,300 refused this invitation, producing a refusal rate of 76 per cent. Given these numbers it seems diligent to suspect that there might be discriminating characteristics related to anti-surveillance or pro-privacy opinions amongst the vast majority of people who could not be contacted or who refused to participate, meaning that this and comparable studies systematically under represent the level of public concern about these issues.

Such surveys effectively handicap the claims-making efforts of privacy advocates who must counteract opinion data that systematically excludes their most strident constituents. Pollsters who conduct such surveys are also given wide interpretive latitude to not just detail their findings but to comment on their implications, often helping to pave the way for future policy developments. For example, in describing the Globe's survey, Allan Gregg, chairman of the firm that conducted the survey, extrapolates from the data to advance the purely editorial hypothesis that if terrorists attacks were to occur in Canada "the government would probably move in with some pretty stiff measures and not meet much public resistance" (CTV, 2005).

Although we do not have data to support this claim, we suspect that differential response to surveys on such topics also contributes to a further democratic deficit. Years of research and teaching on surveillance and privacy suggests that the more knowledgeable people become about such issues, the more they are apt to adopt behaviours that would systematically remove their views from opinion polls. As a result, it is entirely likely that these surveys not only under represent a subset of anti-surveillance attitudes, but in the process also omit segments of the population who are most knowledgeable about such issues.

It is worth noting how comparable dynamics of differential involvement in opinion 
research now threatens to exclude certain categories of people from political and commercial representation more generally. This is due to the eagerness of on-line researchers to augment the detail of their studies by connecting them with data culled from a person's on-line or television surfing patterns. Citizens are enticed to participate in such research through offers of assorted free services and other perks, which they receive in exchange for conducting on-line surveys and installing spyware, cookies and tracking technologies on their television or computer that allow researchers to monitor (often indefinitely) the minutia of their on-line or TV watching behaviour (Tinic, 2006). When combined, this survey and "clickstream" data provide a remarkably detailed set of behavioural information prized by both corporate and political interests. Again, however, one would anticipate that only individuals with the most cavalier attitudes towards surveillance/privacy would allow a company to install spyware on their computer and to have their behaviour tracked in minute detail. The upshot is that citizens with even a modicum of privacy concerns would again be systematically excluded from the forms of opinion and behavioural data used to fashion public policy and commercial ventures.

In light of these concerns we conclude with some practical strategies to address these methodological and political issues. First, scholars and advocates should publicly express their reservations about public opinion polls on surveillance/privacy. Such commentary should not be confined to academic journals, but must also be communicated to politicians, polling firms, privacy advocates, journalists, and the public at large since such audiences present the greatest prospect for effecting timely change. The substance of these critiques should include the types of reservations about response rates detailed above, but must also continue the more familiar forms of critical scrutiny of how such surveys are constructed and interpreted. For example, consider again The Globe and Mail survey. While one of its ostensible findings is that Canadians feel that security must be improved, that conclusion is based on a question that asks: "How well is Canada prepared to deal with a terrorist threat?" The conclusion does not necessarily follow from that question. Citizens might recognize that a country is ill prepared to deal with such threats but also believe that security should not be improved because they recognize that such efforts are ultimately futile in the face of contemporary threats. Alternatively, they might not be willing to tolerate the civil liberties restrictions or absorb the financial costs associated with such policies. This demonstrates the continuing need for vigilance in the face of questionable interpretations or outright manipulations of the results of opinion surveys.

Structural impediments can, however, stand in the way of making such public interventions. This was made obvious when Kevin Haggerty approached the editorial board of The Globe and Mail about the prospect of writing an opinion piece accentuating the types of methodological issues with their study that we detail above. They did not embrace the offer and they ultimately declined to publish the piece he submitted. This is not surprising given that discussions about methodology do not easily fit the media template which prioritizes deviance, action and individualized dramatic narratives (Ericson, Baranek and Chan, 1991). Put succinctly, methodology makes poor copy. More insidious is the way in which media institutions are increasingly sponsoring surveys, marking a transformation from reporting to creating the news. In this context it can be very difficult to persuade a media institution that has just spent tens of thousands of dollars to fund a survey that you would like to write a response that dismantles the 
methodology of that research.

Second, journalists and researchers should routinely and prominently list the response rates for their studies. Although newspaper articles often present the margin of error associated with the random sample drawn for data collection (i.e., "the results of a survey of this size $[\mathrm{n}=100]$ are accurate within 3.1 percentage points, 19 times out of 20 "), it is extremely rare for non-response rates to be reported. While including contact and refusal rates would not immediately rectify the problem of differential response, it is a step towards attuning the public to these issues. The comparative success of efforts to require institutions to report the level of statistical significance of their studies suggests that this is an achievable goal. Indeed, reporting on response rates would probably be an even more valuable development, as it has at least the prospect of being understood by average citizens. It is not difficult to convey why a study with a 76 per cent contact rate should be given greater credence than one where only 10 per cent of eligible respondents were interviewed. Certainly, requiring the public communication of such information would be more beneficial than the current requirements that studies detail their levels of statistical significance, a measure which is only understood by a statistically insignificant percentage of the population (Paulos, 1988).

The practices of private polling firms are of particular concern here. The political economy of such companies often necessitates that they produce quick results from the smallest possible sample size. The response rates for such studies are among the lowest in the research community, although this can be difficult to ascertain. Private firms often do not calculate such rates and if they do they tend not to publicize them. Occasionally such information is treated as proprietary, notwithstanding the formal position of the American Association for Public Opinion Research (2004: 36) that response data should be made available as part of the documentation accompanying any report of survey results. So, when we inquired at the Strategic Counsel about the response rate for their survey for The Globe and Mail we were informed: "it is not our policy to release call disposition data for those survey [sic] which we undertake on behalf of CTV and The Globe and Mail." We were then referred to one of the managing partners of the firm, who was also not very forthcoming when Kevin Haggerty telephoned him to request the response rates:

Managing Partner: Look, I'm not going to give you that information. Our client for that is The Globe and Mail and I'm not going to give you that information. We are a private company and we don't have to deal with these types of request for information... We don't have the time or resources to deal with all of these requests.

Haggerty: So you are telling me that you are simply not going to point me to any of the methodological details for that study?

Managing Partner: We are confident of our methods, they are based on thirty years worth of research methods. I've just returned from vacation and am completely swamped and am going on vacation again in a few days... Look, write me a letter and I'll take it under advisement.

Haggerty: That's it?

Managing Partner: Write me a letter and we will take it under 
advisement.

Approximately five minutes later this individual telephoned Kevin Haggerty to apologize and more sincerely (and civilly) suggest that we send him a request for this information and he would try and make it available. The firm's initial response, however, certainly accentuates the risks of situating the generation of important policy-relevant knowledge in corporations with a less than full commitment to the transparent advancement of knowledge.

Third, if further research confirms our concerns about the disproportion of non-responses for opinion polls on surveillance/privacy, the academic community should investigate adopting measures to weigh some responses relative to others. Weighting, in essence, involves a series of statistical measures to disproportionately value the opinions of some respondents - in this case anti-surveillance or pro-privacy positions - to compensate for the systematic under representation of such opinions from the total sample. Any such effort would first have to overcome the formidable problem of developing accurate empirical knowledge of the disproportionate response rate, although some researchers have already developed proxy measures (Singer, Hoewyk and Neugebauer, 2003). The extra time and financial costs that this would entail would also likely prompt private survey firms to resist such measures. There is also the prospect of negative political reaction to any effort to weigh certain responses, as such procedures can easily be perceived as a politically motivated form of cynical statistical manipulation (Anderson and Fienberg, 1999).

Finally, and perhaps most challengingly, researchers should enter into discussion about whether there is a point beyond which we would not accept the validity of studies on topics that are particularly sensitive to differential response if that research does not achieve a predetermined response rate. Any such effort would involve a degree of courage, as it could easily result in some of our own research being set aside for failing to reach that threshold. Methodological rigor and political honesty suggest that such a commitment is necessary.

\section{References}

The American Association for Public Opinion Research (2004) Standard Definitions: Final Dispositions of Case Codes and Outcome Rates for Surveys, 3rd edition. Lenexa, Kansas: AAPOR.

Anderson, M.J., and S.E. Fienberg (1999) Who Counts? The Politics of Census-Taking in Contemporary America. New York: Russell Sage Foundation.

Coupler, M.P., E. Singer, and R.A. Kulka (1998) Participation in the 1990 Decennial Census. American Politics Quarterly 26:59-80.

CTV (2005) Canadians Split on Anti-Terror Measures: Poll. CTV.ca.

Davis, D.W., and B.D. Silver (2004) Civil Liberties vs. Security: Public Opinion in the Context of the Terrorist Attacks on America. American Journal of Political Science 48:28-46.

Dillman, D. (1991) The Design and Administration of Mail Surveys. Annual Review of Sociology 17:225249. 
Ericson, R.V., P. Baranek, and J. Chan (1991) Representing Order: Crime, Law, and Justice in the News Media. Toronto: University of Toronto Press.

Gandy, O.H. Jr. (2003) Public Opinion Surveys and the Formation of Privacy Policy. Journal of Social Issues 59:283-299.

Goyder, J. (2005) The Dynamics of Occupational Prestige. Canadian Review of Sociology and Anthropology 42:2-23.

Goyder, J., and J. McKenzie Leiper (1985) The Decline in Survey Response: A Social Values Interpretation. Sociology 19:55-71.

Groves, R.M., R.B. Cialdini, and M.P. Couper (1992) Understanding the Decision to Participate in a Survey. Public Opinion Quarterly 56:475-495.

Groves, R.M., and M.P. Couper (1998) Nonresponse in Household Interview Surveys. New York: John Wiley and Sons.

Haggerty, K.D., and R.V. Ericson (eds.) (2006) The New Politics of Surveillance and Visibility. Toronto: University of Toronto Press.

Herbst, S. (1993) Numbered Voices: How Opinion Polling Has Shaped American Politics. Chicago: University of Chicago Press.

Herbst, S. (1998) Reading Public Opinion. Chicago: University of Chicago Press.

Howard, P.N., J.N. Carr, and T.J. Milstein (2005) Digital Technology and the Market for Political Surveillance. Surveillance and Society 3:59-73.

Huddy, L., N. Khativ, and T. Capelos (2002) The Polls - Trends: Reactions to the Terrorist Attacks of September 11, 2001. Public Opinion Quarterly 66:418-450.

Newman, D.W. (2003) September 11: A Societal Reaction Perspective. Crime, Law and Social Change 39:219-231.

Paulos, J.A. (1988) Innumeracy: Mathematical Illiteracy and Its Consequences. New York: Hill and Wang.

Schleifer, S. (1986) Trends in Attitudes Toward and Participation in Survey Research. Public Opinion Quarterly 50:17-26.

Singer, E., J.Van Hoewyk, and R.J. Neugebauer (2003) Attitudes and Behavior: The Impact of Privacy and Confidentiality Concerns on Participation in the 2000 Census. Public Opinion Quarterly 67:368-384.

Tinic, S. (2006) (En)Visioning the Televisual Audience: Revisiting Questions of Power in the Age of Interactive Television. In The New Politics of Surveillance and Visibility, edited by K.D. Haggerty and R.V. Ericson. Toronto: University of Toronto Press.

Wall, D. (2006) Surveillant Internet Technologies and the Growth of Information Capitalism: Spams and Public Trust in the Information Society. In The New Politics of Surveillance and Visibility, edited by K.D. Haggerty and R.V. Ericson. Toronto: University of Toronto Press. 